\title{
Seasonal variation and influence factors of organophosphate esters in air particulate matter of a northeastern Chinese test home
}

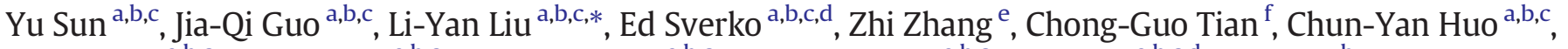 \\ Hai-Ling Li ${ }^{\text {a,b,c }}$, Wan-Li Ma ${ }^{\text {a,b,c }}$, Zi-Feng Zhang ${ }^{\text {a,b,c }}$, Wei-Wei Song ${ }^{\text {a,b,c }}$, Yi-Fan Li ${ }^{\text {a,b,c,d }}$, Li Wang ${ }^{\text {b }}$ \\ a International Joint Research Center for Persistent Toxic Substances (IJRC-PTS)/International Joint Research Center for Arctic Environment and Ecosystem (IJRC-AEE), State Key Laboratory of Urban \\ Water Resource and Environment, Harbin Institute of Technology, Harbin 150090, China \\ ${ }^{\mathrm{b}}$ School of Environment, Harbin Institute of Technology, Harbin 150090, China \\ c University Corporation for Polar Research, Beijing 100875, China \\ d IJRC-PTS-NA, Toronto M2N 6X9, Canada \\ e College of Agricultural Resource and Environment, Heilongjiang University, Harbin 150080, China \\ ${ }^{\mathrm{f}}$ Key Laboratory of Coastal Environmental Processes and Ecological Remediation, Yantai Institute of Coastal Zone Research, CAS, Yantai 264003, China
}

\section{H I G H L I G H T S}

- The $\sum_{12} \mathrm{OPEs}$ concentrations in spring and summer were higher than those in autumn and winter.

- Outdoor TSP was the main factor that affected the OPE concentration variation in PM samples.

- The absorption mechanism dominates the G/P partitioning and the D-E model estimates were more reliable.

- EDIs and CRs posed by OPEs via indoor air and dust were low, indicating a safe threshold.

\section{A R T I C L E I N F O}

\section{Article history:}

Received 24 March 2020

Received in revised form 3 June 2020

Accepted 5 June 2020

Available online 8 June 2020

Editor: Adrian Covaci

\section{Keywords:}

Organophosphate esters

Particulate matter

Seasonal variation

Influence factors

Carcinogenic risk
G R A P H I C A L A B S T R A C T

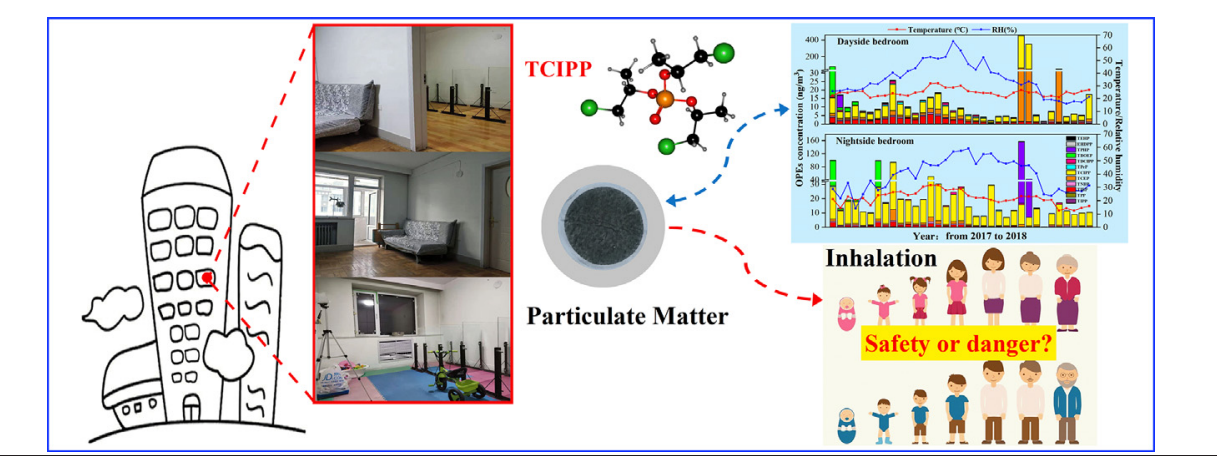

\section{A B S T R A C T}

To investigate the seasonal variation of organophosphate esters (OPEs) in air particulate matter (PM) and the corresponding influence factors in indoor environment, 104 indoor PM samples were collected in a test home, Harbin, China, from March 2017 to March 2018. The $\Sigma_{12}$ OPEs concentrations ranged from $0.41 \mathrm{ng} / \mathrm{m}^{3}$ to $940 \mathrm{ng} / \mathrm{m}^{3}$. Tris(1-chloro-2-propyl) phosphate (TCIPP) was the most abundant OPE and accounted for $83.2 \%$ of the total OPEs. The $\Sigma_{12}$ OPEs concentrations in spring and summer were higher than those in autumn and winter. Outdoor total suspended particles (TSP) were the main factor that affected the concentration variation of OPEs in PM samples in the test home. Comparisons of the gas/particle (G/P) partitioning equilibrium models indicated that the Dachs-Eisenreich (D-E) model estimates were more reliable than the other models in this study. The particle fractions of OPEs with $\log K_{\mathrm{OA}}>10.51$ that predicted by all four models generally well matched the measured OPE particle fractions in the literatures. To OPEs with lower molecular weight, inhalation was the main exposure route and ingestion contributed mostly to OPEs with higher molecular weight. In addition, the estimated daily intakes (EDIs) and carcinogenic risks (CRs) posed by OPEs were all below the recommended values, indicating that the current OPE levels in the test home were within the safe thresholds.

c) 2020 Elsevier B.V. All rights reserved.

* Corresponding author at: International Joint Research Center for Persistent Toxic Substances (IJRC-PTS)/International Joint Research Center for Arctic Environment and Ecosystem (IJRC-AEE), State Key Laboratory of Urban Water Resource and Environment, Harbin Institute of Technology, Harbin 150090, China.

E-mail address: llyan7664@163.com (L.-Y. Liu). 


\section{Introduction}

Organophosphate esters (OPEs) are widely applied as flame retardants (FRs) and/or plasticizers in consumer products and building materials (Van der Veen and de Boer, 2012). With the gradual phase-out or restriction of brominated flame retardants (BFRs), OPEs as substitutes, the worldwide production is expected to increase from 500,000 tons in 2011 to 680,000 tons in 2015 (Wang et al., 2015; Wei et al., 2015). In China, the OPE annual yield reached approximately 70,000 tons in 2007 and is expected to reach 400,000 tons in 2020 (Wei et al., 2015). OPEs can be slowly released to the surrounding environment via abrasion, volatilization, and leaching since most OPEs are used as additives in products (Wensing et al., 2005), resulting in their universally detections in indoor environments (Yang et al., 2014; Mizouchi et al., 2015; Zheng et al., 2015; Kim et al., 2019; Li et al., 2019), as well as air (Li et al., 2018; Cao et al., 2019b), waters (Lai et al., 2019), sediments (Tan et al., 2016), and soils (Wan et al., 2016) in outdoor environments. Some OPEs, such as tri-n-butyl phosphate (TNBP), tris(2-chloroethyl) phosphate (TCEP), tris(1,3-dichloroisopropyl) phosphate (TDCIPP), and tris(2-ethylhexyl) phosphate (TEHP), are suspected to be carcinogenic (Van der Veen and de Boer, 2012; Wei et al., 2015; USEPA, 2020). Considering the carcinogenicity and the increasing application in indoors, health risks to OPEs in indoor environments where people spend $>20 \mathrm{~h}$ of their time, have received significant attention from the scientific community (Abdallah and Covaci, 2014; Araki et al., 2014; Hou et al., 2016).

Once migrated to the indoor air, OPEs are not easy to degrade due to the relatively closed nature of the indoor environments (e.g., low light and poor air circulation) and will be persistent in indoors and be inhaled by human eventually. Hence, indoor air is an important source of human exposure to OPEs. Currently, studies on OPE contamination in indoor air have been conducted in a variety of microenvironments, including homes (Zhou et al., 2017; Kim et al., 2019), offices (Yang et al., 2014; Tao et al., 2019), dormitories (Cao et al., 2019a) and so on. However, most of these published studies have focused on a one-time sampling to explore the differences among various microenvironments, which is hard to reflect the temporal variations that have been confirmed in the outdoor atmosphere (Li et al., 2018; Pang et al., 2019; Zhang et al., 2019). In addition, for the outdoor environments, the influence factors are complex and changeable, such as the large difference of the temperature, total suspended particles (TSP), wind speed, rainfall and snow, and the introduction of pollution sources, etc. Field measurements conducted in a test home show big advantages in investigating the influence factors of OPE concentrations due to the relative stability in indoor environments.

The partitioning of OPEs between gas and particle phase air can determine their exposure pathways. Most OPEs are generally considered as particle-bounded compounds since their mainly detections in particles, including TNBP, TCEP, TCIPP, TDCIPP, tris(2-butoxyethyl) phosphate (TBOEP), triphenyl phosphate (TPHP), and TEHP (Moller et al., 2011; Salamova et al., 2014). However, Wolschke et al. and Sühring et al. believed $>75 \%$ or even $99 \%$ of TCIPP presented in gas phase, rather than absorbed to atmospheric particles in the atmosphere (Suhring et al., 2016; Wolschke et al., 2016). Therefore, considering the wide ranges of OPE physicochemical properties, the OPE gas/particle (G/P) partitioning still needs further explored. So far, the Junge-Pankow (JP) model, Harner-Bidleman (H-B) model, Dachs-Eisenreich (D-E) model, and poly-parameter liner free energy relationship (pp-LFER) model for outdoor atmosphere have been introduced to estimate the $\mathrm{G} / \mathrm{P}$ partitioning of OPEs in indoor air (Okeme et al., 2018; Salthammer and Goss, 2019). The J-P model is an adsorption model based on subcooled vapor pressure $\left(P_{\mathrm{L}}^{\mathrm{o}}\right)$ while the absorption $\mathrm{H}-\mathrm{B}$ model is based on the octanol/air partition coefficient $\left(K_{\mathrm{OA}}\right)$ (Pankow, 1987; Harner and Bidleman, 1998). The D-E model considers both absorption and adsorption mechanisms whereas the pp-LFER model relates the gas-particle partition coefficients to the Gibb's free energies
(Dachs and Eisenreich, 2000; Goss, 2005). The mechanism affecting the partitioning needs to be further clarified.

Hence, the main aims of this study were a) to investigate the concentrations, profiles, and seasonal variation of 12 OPEs in a northeastern Chinese test home; b) to explore the influence factors and potential sources of these OPEs; $c$ ) to predict the OPE particle fractions based on the four models above and to analyze the possible mechanism that affects the G/P partitioning in indoor air; and d) to estimate human exposure and risk assessment of OPEs via inhalation, ingestion, and dermal absorption.

\section{Materials and methods}

\subsection{Chemicals and reagents}

Twelve OPEs were investigated, including tri-isopropyl phosphate (TIPP, 95\%), tripropyl phosphate (TPP, 99.7\%), tri-n-butyl phosphate (TNBP, 100\%), tris(2-chloroethyl) phosphate (TCEP, 100\%), tris(1chloro-2-propyl) phosphate (TCIPP, including three isomers, 96.0\%), tripentyl phosphate (TPeP, 97.2\%), tris(1,3-dichloroisopropyl) phosphate (TDCIPP, 99.8\%), tris(2-butoxyethyl) phosphate (TBOEP, 93.3\%), triphenyl phosphate (TPHP, 99.9\%), 2-ethylhexyl diphenyl phosphate (EHDPP, 91.0\%), tris(2-ethylhexyl) phosphate (TEHP, 97.0\%) purchased from AccuStandard (New Haven, CT, USA), tri-isobutyl phosphate (TIBP, 99.8\%), tri-n-butyl phosphate- $d_{27}$ (TNBP- $\left.d_{27}, 99.1 \%\right)$, triphenyl phosphate- $d_{15}$ (TPHP- $d_{15}, 99.1 \%$ ) purchased from Chiron AS (Trondheim, Norway). All solvents used for this study were pesticide residue analysis grade and purchased from J.T. Baker (Phillipsburg, NJ, USA).

\subsection{Sample collection}

The test home (built in 1994, Fig. S1) is a three-bedroom, one-living room, one-kitchen, two-bathroom $90 \mathrm{~m}^{2}$ decorated home on the fifth floor (a total of seven floors) in Harbin, northeastern China. The details of the test home are described in supplementary material (SM) S1.1. In this study, 104 indoor air samples were collected from March 2017 to March 2018. The sampling devices were placed near the center of two bedrooms with different orientations (dayside and nightside), and sampling took place at $1.5 \mathrm{~m}$ above the ground. Air samples were also collected from the living room since September when haze usually occurred to investigate the effect of TSP. All adjacent doors were closed while the windows were open occasionally during the non-heating season to simulate common conditions during home hours. A low volume air sampling pump (OMINI5000, Connal Environmental., Shanghai, China) was connected to a quartz fiber filter (QFF, Ф25 mm, Whatman, UK) to collect suspended particulate matter (PM) every eight days at a flow rate of $2 \mathrm{~L} / \mathrm{min}$, avoiding a big interference on air flow. Prior to sampling, QFF filters were baked at $450{ }^{\circ} \mathrm{C}$ for $6 \mathrm{~h}$ to remove any residual organic matter. QFF filters were equilibrated in a desiccator for $24 \mathrm{~h}$ before weighing in both pre- and post- sample collection to obtain total suspended particles mass. Gravimetric measurements were conducted with a high precision $(0.00001 \mathrm{~g})$ balance. The PM was sampled for a continuous $48 \mathrm{~h}$ to obtain sufficient PM mass. The total sampling air volume was $5.76 \mathrm{~m}^{3}$. After weighing, filters were folded to avoid the particle loss and were wrapped in aluminum foil, followed by storage in a refrigerator at $-20^{\circ} \mathrm{C}$ before analysis. The temperature, relative humidity $(\mathrm{RH})$, and TSP in the test home are provided in Table S1. Meteorological data including air quality index (AQI), $\mathrm{PM}_{10}$, and $\mathrm{PM}_{2.5}$ from the outdoors were recorded during the sampling process.

\subsection{Sample preparation and analysis}

A circle with a diameter of $8 \mathrm{~mm}$ was cut down from the QFF filter for organic carbon (OC) and elemental carbon (EC) determination. The rest filter was spiked with $100 \mathrm{ng}$ of TnBP- $d_{27}$ and TPHP- $d_{15}$ in $10 \mathrm{~mL}$ glass centrifuge tube and equilibrated for $3 \mathrm{~h}$ at room 
temperature. The samples were extracted by shaking for $30 \mathrm{~min}$ with $10 \mathrm{~mL}$ dichloromethane/hexane (3:1, v/v), followed by centrifugation at $4000 \mathrm{rpm}$ for $5 \mathrm{~min}$. The upper layer was transferred to a new tube. The extraction was repeated for three times and all the extraction solvents were combined. Finally, the solvent was concentrated to $1 \mathrm{~mL}$ for instrumental analysis at room temperature under a gentle stream of $\mathrm{N}_{2}$ (Ultrahigh purity grade, 99.999\%) with Automated Evaporation System (TurboVap II, Biotage, Charlotte, NC, USA) to reduce air exposure.

OC and EC were analyzed with the Thermal/Optical Carbon Analyzer (2001 A, Desert Research Institute, Las Vegas, NV, USA). OPEs were analyzed on an Agilent 7890 gas chromatography system coupled to an Agilent 5977A mass spectrometry, operated in electron impact ionization (EI) mode with a DB-5MS column ( $30 \mathrm{~m} \times 0.25 \mathrm{~mm} \times 0.25 \mu \mathrm{m})$ according to the method previously published (Van den Eede et al., 2012). Briefly, $1 \mu$ of the final extract was injected using cold splitless injection. The GC temperature program was $90{ }^{\circ} \mathrm{C}$ initially, hold $1.25 \mathrm{~min}$, ramp $10{ }^{\circ} \mathrm{C} / \mathrm{min}$ to $240{ }^{\circ} \mathrm{C}$, ramp $20^{\circ} \mathrm{C} / \mathrm{min}$ to $310^{\circ} \mathrm{C}$, hold $16 \mathrm{~min}$. Helium was used as a carrier gas with a flow rate of $1.0 \mathrm{~mL} / \mathrm{min}$. The detail information is presented in Table S3.

\section{4. $\mathrm{QA} / \mathrm{QC}$ and statistical analysis}

Only TCIPP was detected at low level $(1.41 \pm 0.83 \mathrm{ng})$ in blank QFF filters, and it was subtracted from that in real samples. Other OPEs were below the detection limits. All the samples were spiked with TNBP- $d_{27}$ and TPHP- $d_{15}$ to monitor the recoveries. The mean recoveries were $122 \pm 12 \%$ and $123 \pm 6.2 \%$ for TNBP- $d_{27}$ and TPHP- $d_{15}$, respectively. For each 20 samples, 3 field blanks and 3 method spikes were processed. The mean recoveries of target compounds in spiked samples ranged from $76.0 \pm 9.3 \%$ to $115 \pm 19 \%$. All the OPE concentrations in filter samples were corrected with blank values and recoveries. The limits of quantification (LOQ) were calculated from the lowest concentration of the calibration curve with a nominal sampling volume of $5.76 \mathrm{~m}^{3}$. The LOQs of 12 OPEs ranged from $0.17 \mathrm{ng} / \mathrm{m}^{3}$ to $3.1 \mathrm{ng} / \mathrm{m}^{3}$. For statistical analysis, the concentrations measured in real samples below LOQs were replaced by $\mathrm{LOQ} / 2$ values. All the statistical analysis was performed by SPSS software (Version 24). The detail information and the parameters used of four equilibrium models (J-P model, H-B model, D-E model, and pp-LFER model), human exposure, and risk assessment are shown in SM S2-S3.

\section{Results and discussion}

\subsection{Concentrations, profiles, and seasonal variation of OPEs in test home}

\subsubsection{Concentrations, profiles, and seasonal variation of OPEs in two bedrooms}

OPEs were found in all air PM samples from the two bedrooms. Eight of twelve target OPEs (TPP, TIBP, TNBP, TCEP, TCIPP, TDCIPP, TPHP, and TEHP) were found in $>75 \%$ of samples while TBOEP and EHDPP were found in $<30 \%$ in both dayside and nightside bedrooms (Table 1 ). The median $\Sigma_{12}$ OPEs concentrations were $9.1 \mathrm{ng} / \mathrm{m}^{3}$ (ranging: $1.8-460 \mathrm{ng} /$ $\mathrm{m}^{3}$; mean: $35 \pm 93 \mathrm{ng} / \mathrm{m}^{3}$ ) and $15 \mathrm{ng} / \mathrm{m}^{3}$ (ranging: $0.41-160 \mathrm{ng} / \mathrm{m}^{3}$; mean: $27 \pm 33 \mathrm{ng} / \mathrm{m}^{3}$ ) in dayside and nightside bedrooms, respectively. As far as we know, the concentration of OPEs in air varies with the type of samples, such as gas phase, particle phase or both. Therefore, it is necessary to point out the type of air samples when comparing with other studies (Table S4). The $\Sigma_{7}$ OPEs concentrations in gas phase samples from bedrooms in Canada, the USA, and the Czech Republic were detected at levels of 12.3-4870 $\mathrm{ng} / \mathrm{m}^{3}$ (median: $89.2 \mathrm{ng} / \mathrm{m}^{3}$ ), $0.28-356 \mathrm{ng} / \mathrm{m}^{3}$ (median: $41.5 \mathrm{ng} / \mathrm{m}^{3}$ ), and $5.59-211 \mathrm{ng} / \mathrm{m}^{3}$ (median: $23.0 \mathrm{ng} / \mathrm{m}^{3}$ ), respectively (Vykoukalova et al., 2017). In bedrooms in Japan, the $\Sigma_{8}$ OPEs concentrations ranged from 55 to $415 \mathrm{ng} / \mathrm{m}^{3}$ (median: $222 \mathrm{ng} / \mathrm{m}^{3}$ ), and the air samples included both gas and particle phases (Takeuchi et al., 2014). The concentration of $\Sigma_{8}$ OPEs, including both gas and particle phases, in a bedroom from Sweden was found to be $162 \mathrm{ng} / \mathrm{m}^{3}$ (Marklund et al., 2005). Therefore, the $\Sigma_{12}$ OPEs concentrations in bedrooms in Harbin test home were much lower than those in Canada, the USA, and the Czech Republic since only gas phase was considered in these reported concentrations while OPEs in particle phase contributed more (Carlsson et al., 1997). And the concentrations of $\Sigma_{12}$ OPEs in this study were similar to those in Japan and Sweden.

For both dayside and nightside bedrooms samples, TCIPP was the dominant OPE, followed by TCEP, TIBP, and TNBP. Similar results have been reported on both indoor (Luongo and Ostman, 2016; He et al., 2018; Wang et al., 2019) and outdoor atmosphere (Li et al., 2018). The median TCIPP concentrations were $3.9 \mathrm{ng} / \mathrm{m}^{3}$ (ranging: nd-390 ng/ $\mathrm{m}^{3}$; mean: $24 \pm 80 \mathrm{ng} / \mathrm{m}^{3}$ ) and $12 \mathrm{ng} / \mathrm{m}^{3}$ (ranging: nd- $80 \mathrm{ng} / \mathrm{m}^{3}$; mean: $15 \pm 13 \mathrm{ng} / \mathrm{m}^{3}$ ) in dayside and nightside bedrooms, respectively. As well, all air PM samples were dominated by $\Sigma_{\mathrm{Cl}} \mathrm{OPEs}$ (sum of three chlorinated OPEs; TCEP, TCIPP, and TDCIPP), accounting for $62.2 \pm 18.7 \%$ and $79.5 \pm 26.0 \%$ of the $\Sigma_{12}$ OPEs in dayside and nightside bedrooms, respectively. The abundance of chlorinated OPEs especially TCIPP can be attributed to the more widely commercial use (Andresen et al., 2004; Van der Veen and de Boer, 2012), more persistent properties (Liang

Table 1

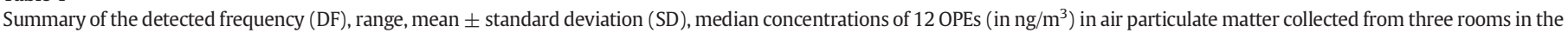
test home in Harbin, China, and ratio of chlorinated OPEs (\%).

\begin{tabular}{|c|c|c|c|c|c|c|c|c|c|c|c|c|}
\hline \multirow[t]{2}{*}{ OPES } & \multicolumn{4}{|c|}{ Dayside bedroom $(n=36)$} & \multicolumn{4}{|c|}{ Nightside bedroom $(n=38)$} & \multicolumn{4}{|c|}{ Living room $(n=30)$} \\
\hline & DF & Range & Mean \pm SD & Median & $\mathrm{DF}$ & Range & Mean \pm SD & Median & $\mathrm{DF}$ & Range & Mean \pm SD & Median \\
\hline TIPP & 77.8 & nd-0.32 & $0.05 \pm 0.06$ & 0.03 & 68.4 & nd-0.42 & $0.06 \pm 0.09$ & 0.04 & 56.7 & nd-0.12 & $0.02 \pm 0.03$ & 0.01 \\
\hline ТPP & 97.2 & nd-0.36 & $0.09 \pm 0.09$ & 0.05 & 92.1 & nd-0.26 & $0.07 \pm 0.07$ & 0.06 & 86.7 & nd-0.27 & $0.06 \pm 0.08$ & 0.03 \\
\hline TIBP & 100 & $0.11-5.6$ & $1.9 \pm 1.4$ & 1.8 & 97.4 & nd-3.4 & $0.97 \pm 0.90$ & 0.58 & 100 & $0.02-1.8$ & $0.45 \pm 0.38$ & 0.34 \\
\hline TNBP & 100 & $0.06-0.96$ & $0.47 \pm 0.26$ & 0.49 & 100 & $0.01-1.4$ & $0.44 \pm 0.28$ & 0.40 & 100 & nd-5.3 & $0.51 \pm 1.0$ & 0.21 \\
\hline TCEP & 100 & $0.16-60$ & $5.2 \pm 14$ & 0.89 & 94.7 & nd-7.8 & $1.0 \pm 1.3$ & 0.75 & 96.7 & nd-15 & $3.7 \pm 3.6$ & 2.9 \\
\hline TCIPP & 97.2 & nd-390 & $24 \pm 80$ & 3.9 & 97.4 & nd-80 & $15 \pm 13$ & 12 & 100 & $3.4-930$ & $120 \pm 180$ & 54 \\
\hline TPeP & 100 & $0.03-0.96$ & $0.30 \pm 0.25$ & 0.23 & 63.2 & nd-1.1 & $0.14 \pm 0.20$ & 0.08 & 40.0 & nd-1.1 & $0.09 \pm 0.23$ & nd \\
\hline TDCIPP & 77.8 & nd-2.66 & $0.48 \pm 0.64$ & 0.25 & 84.2 & nd-1.6 & $0.38 \pm 0.37$ & 0.25 & 80.0 & nd-2.6 & $0.60 \pm 0.54$ & 0.55 \\
\hline TBOEP & 13.9 & nd-62 & $2.1 \pm 10$ & nd & 13.2 & nd-70 & $3.8 \pm 16$ & nd & 6.7 & nd-9.7 & $0.37 \pm 1.8$ & nd \\
\hline ТРHP & 100 & $0.01-7.3$ & $0.28 \pm 1.2$ & 0.06 & 97.4 & nd-138 & $4.6 \pm 23$ & 0.04 & 100 & $0.01-1.1$ & $0.20 \pm 0.23$ & 0.12 \\
\hline EHDPP & 19.4 & nd-0.12 & $0.02 \pm 0.04$ & nd & 23.7 & nd-0.05 & $0.01 \pm 0.01$ & nd & 30.0 & nd-0.07 & $0.01 \pm 0.02$ & nd \\
\hline TEHP & 91.7 & nd-0.51 & $0.15 \pm 0.13$ & 0.11 & 71.1 & nd-2.9 & $0.17 \pm 0.48$ & 0.04 & 93.3 & nd-0.31 & $0.08 \pm 0.08$ & 0.05 \\
\hline$\Sigma_{\mathrm{Cl}} \mathrm{OPEs} \mathrm{s}^{\mathrm{a}}$ & 100 & $0.27-450$ & $29 \pm 93$ & 5.5 & 97.4 & nd-89 & $16 \pm 15$ & 13 & 100 & $5.0-940$ & $130 \pm 190$ & 57 \\
\hline$\Sigma_{12} \mathrm{OPES}$ & 100 & $1.8-460$ & $35 \pm 93$ & 9.1 & 100 & $0.41-160$ & $27 \pm 33$ & 15 & 100 & $6.8-940$ & $130 \pm 190$ & 59 \\
\hline$\Sigma_{\mathrm{Cl} / 12} \mathrm{OPES}$ & & $14.7-99.5$ & $62.2 \pm 18.7$ & 62.8 & & $0-97.3$ & $79.5 \pm 26.0$ & 88.8 & & 29.0-99.9 & $91.8 \pm 16.2$ & 97.9 \\
\hline
\end{tabular}

\footnotetext{
a Sum of the chlorinated OPEs, including TCEP, TCIPP and TDCIPP.
} 
and Liu, 2016), and relatively higher vapor pressure (except TDCIPP) than most non-chlorinated OPEs (Van der Veen and de Boer, 2012).

Statistical analysis revealed that the $\Sigma_{12}$ OPEs levels (especially TCIPP) in nightside bedroom were significantly higher than those concentrations found in dayside bedroom (paired-samples $t$-test, $\mathrm{p}<0.01$ ) when the influence of haze was not taken into account (Table S6). Direct photodegradation has a limited contribution on most OPE natural transformations due to their low absorption within the solar spectrum radiation (Cristale et al., 2017), indirect photodegradation caused by sunlight cannot be ignored between the two different orientation bedrooms. The significant difference between dayside and nightside bedrooms may be also a result of different locations (discussed below). However, the strong correlations for individual OPE concentrations between dayside and nightside bedrooms may be explained for the indoor air circulation (Table S7).

Due to the particularity of climate in Harbin, the seasons are divided as follows: spring (from April to May); summer (from July to August); autumn (from September to October); winter (from November to March). The concentrations of individual and total OPEs associated with airborne PM are illustrated in Fig. 2. The median OPE concentrations for four seasons in nightside bedroom (spring: $19.0 \mathrm{ng} / \mathrm{m}^{3}$; summer: $19.6 \mathrm{ng} / \mathrm{m}^{3}$; autumn: $9.98 \mathrm{ng} / \mathrm{m}^{3}$; winter: $10.6 \mathrm{ng} / \mathrm{m}^{3}$ ) were significantly higher than those in dayside bedroom (spring: $12.4 \mathrm{ng} /$ $\mathrm{m}^{3}$; summer: $10.2 \mathrm{ng} / \mathrm{m}^{3}$; autumn: $4.41 \mathrm{ng} / \mathrm{m}^{3}$; winter: $5.70 \mathrm{ng} / \mathrm{m}^{3}$ ). However, the overall trends of seasonal variation for bedrooms with different orientations were basically the same. The $\Sigma_{12}$ OPEs concentrations in spring and summer were higher than those in autumn and winter. The significant positive correlation between the $\Sigma_{12}$ OPEs concentration and the temperature may explain the phenomenon (Table S9). Wang et al. have reported that the indoor $\mathrm{PM}_{2.5}$-bound $\Sigma_{9}$ OPEs concentrations generally increased in summer (June to August 2016) and heating seasons (November 2016 to February 2017) (Wang et al., 2019). However, no elevated OPE concentrations in heating seasons were observed here due to the low TSP concentrations in bedrooms (Table S8). In addition, few studies on the OPE seasonal variation in indoor air and various literatures on the positive correlation of OPEs between indoor air and dust (Xu et al., 2016; Vykoukalova et al., 2017; Tao et al., 2019), the results were compared with literature on OPE seasonal variation in indoor dust. The OPE concentrations in office dust were higher in spring (March to April 2012), and they were the lowest in summer (July and August 2012) (Cao et al., 2014). However, these results were contrary to the high OPE concentrations in PM in summer in this study. The main reason for this difference may be that the more frequent ventilation accelerated the OPE migration from dust into air in offices, whereas lower ventilation effectively prevented the dilution effect of outdoor air and ensured the retention of OPEs in PM in the test home.

\subsubsection{Concentrations and profiles of OPEs in living room}

Similar to bedrooms, most OPEs were also found in air PM samples in the living room (Table 1 ). The median $\Sigma_{12}$ OPEs concentration was $59 \mathrm{ng} / \mathrm{m}^{3}$ (ranging: $6.8-940 \mathrm{ng} / \mathrm{m}^{3}$; mean: $130 \pm 190 \mathrm{ng} / \mathrm{m}^{3}$ ) in living room. TCIPP was the most abundant OPE and accounted for $83.7 \pm$ $18.7 \%$ of the total concentration. $\Sigma_{\mathrm{Cl}} \mathrm{OPEs}$ accounted for $91.8 \pm 16.2 \%$ of the $\Sigma_{12}$ OPEs concentration in living room and its percentage was much higher than that in bedrooms (Table 1). The higher TSP (Table S1) and the corresponding higher concentrations of TCEP and TCIPP in PM in the living room, resulting in an increasing percentage of chlorinated OPEs, indicated that chlorinated OPEs were more easily accumulated in PM than non-chlorinated OPEs. Most previous studies have analyzed the OPEs in both gas and particle phases in living rooms (Table S5). The median $\Sigma_{12}$ OPEs concentrations in living room in Harbin test home were similar to those in Japan (Saito et al., 2007; Kanazawa et al., 2010; Takeuchi et al., 2014; Takeuchi et al., 2018), Germany (Zhou et al., 2017), Sweden (Marklund et al., 2005; Bergh et al., 2010), and Norway (Cequier et al., 2014; Xu et al., 2016).
Only the concentrations of bedrooms and living room for the same sampling period (from September 11th, 2017 to March 29th, 2018) were compared. Statistical analysis of $\Sigma_{12}$ OPEs levels revealed significant difference (Mann-Whitney $U$ test, $\mathrm{p}<0.01$ ) between bedrooms and living room (Table S8). As mentioned above, the main components that cause this difference were the higher concentrations of TCIPP $(\mathrm{p}<0.01)$ and TCEP $(\mathrm{p}<0.05)$ in living room. And the significantly higher $\Sigma_{12} \mathrm{OPEs}$ concentration in living room might be a result of a higher TSP in PM $(\mathrm{p}<0.05$, discussed below).

\subsection{Influence factors of OPEs in different rooms and possible sources}

\subsubsection{Temperature and relative humidity}

In this study, significant $(\mathrm{p}<0.05)$ positive correlations between $\Sigma_{12}$ OPEs, TIBP, TCEP, TDCIPP concentrations and temperature were found. Since OPEs, especially with lower molecular weight, are semivolatile compounds and not chemically bonded to the original materials, OPEs can be slowly released into the environment with the increase in the temperature, resulting in higher OPE concentrations during warmer months (including spring and summer) (Fig. 1).

Water (i.e., $\mathrm{RH}$ ) can influence the $\mathrm{OH}$-initiated heterogeneous oxidation of TBOEP via influencing the phase of particles, subsequently influence the mixing state and reactivity (Liu et al., 2014a; Liu et al., 2019). Furthermore, Li et al. have revealed that $\mathrm{RH}$ could retard the reaction rate of $\cdot \mathrm{OH}$ initiated heterogeneous oxidation of gaseous TCIPP and subsequently hindered the gaseous TCIPP degradation, implying the varied concentrations upon different humidity conditions (Li et al., 2017a). A significant negative correlation was observed between $\mathrm{RH}$ and particulate TBOEP ( $p<0.05$, Table S9), which is consistent with the finding that increased RH promotes TBOEP degradation via decreasing the viscosity of particle (Liu et al., 2014a; Liu et al., 2019). However, other hydrophilic OPEs including TCIPP and TCEP, the two important chlorinated OPEs with higher detection rates and measured concentrations in this study, did not possess a similar trend, indicating that the effect of $\mathrm{RH}$ may be obscured by other influence factors such as a more significant positive correlation with temperature of TCEP. Moreover, humidity had a negative influence on the particle concentration $(r=-0.31$, $\mathrm{p}<0.01$, Table S10), thereby affecting the OPE concentrations in PM.

\subsubsection{API, $P M_{10}, P M_{2.5}$ and TSP}

In terms of meteorological factors, the outdoor AQI, $\mathrm{PM}_{10}$, and $\mathrm{PM}_{2.5}$ were recorded and the indoor TSP were collected during the sampling period, finding that the indoor air quality was closely associated with ambient outdoor atmosphere quality, especially $\mathrm{PM}_{2.5}(r=0.69$, $\mathrm{p}<0.01$, Table S10) (Fromme et al., 2005). Furthermore, significant positive correlations were found between particle-bound OPEs, especially TCEP and TCIPP concentrations, and AQI, $\mathrm{PM}_{10}, \mathrm{PM}_{2.5}$, and TSP levels, indicating their ability of massively accumulated in indoor PM as a main carrier under the heavy pollution condition. Similar results have been found during outdoor heavy haze pollution condition (Cao et al., 2019b). Compared with bedrooms, the living room is more vulnerable to the impact of ambient outdoor atmosphere because of its proximity to the balcony (Fig. S1), especially during the heavy pollution condition, resulting in significantly higher TSP ( $p<0.05$, Table S8) may be an important reason for higher $\Sigma_{12}$ OPEs concentration in living room. And emphasize the importance of avoiding indoor and outdoor air circulation during the heavy pollution period from the perspective of OPE pollution. The temperature, $\mathrm{RH}$, and TSP are all influence factors that affect the OPE concentrations in the test home, however, the stronger correlation ( $r=0.44, \mathrm{p}<0.001$, Table S9) indicated that the indoor TSP, greatly affected by outdoor TSP $(r>0.65, \mathrm{p}<0.001$, Table S10), was the main influence factor.

\subsubsection{OC and EC}

In order to further study which component the OPEs in particles are bounded to, thereby affecting the gas/particle partitioning, the $\mathrm{OC}$ and 




Fig. 1. Concentrations and profile of OPEs in air particle matter from dayside bedroom (A) and nightside bedroom (B).

EC were measured. The concentrations of OC and EC were 2.0-97.8 $\mu \mathrm{g} \mathrm{C/}$ $\mathrm{m}^{3}$ (median: $6.3 \mu \mathrm{g} \mathrm{C} / \mathrm{m}^{3}$ ) and $0.1-26.9 \mu \mathrm{g} \mathrm{C} / \mathrm{m}^{3}$ (median: $1.0 \mu \mathrm{g} \mathrm{C} / \mathrm{m}^{3}$ ), respectively. Significant positive correlations were found between the concentrations of $\Sigma_{12}$ OPEs, TCEP, TCIPP, TDCIPP, TBOEP, and TPHP with OC and EC concentrations (Table S9). In previous studies, it has been found that substrate effect of black carbon (i.e., EC) on OPEs might have a negative impact on the OPE degradation rates, leading to elevated OPE concentrations (Liu et al., 2014b). Also, the correlations between OPEs and OC were more significant than those between OPEs and EC, indicating the absorption effect of organic matter on OPEs. However, not all OPEs, especially with lower molecular weight (e.g., TIPP, TIBP), were positively correlated with OC or EC, which might result in the different partitioning mechanism of OPE gas/particle partitioning (Shen et al., 2011). Similar results have been reported on phthalates in outdoor atmosphere (Ma et al., 2014).

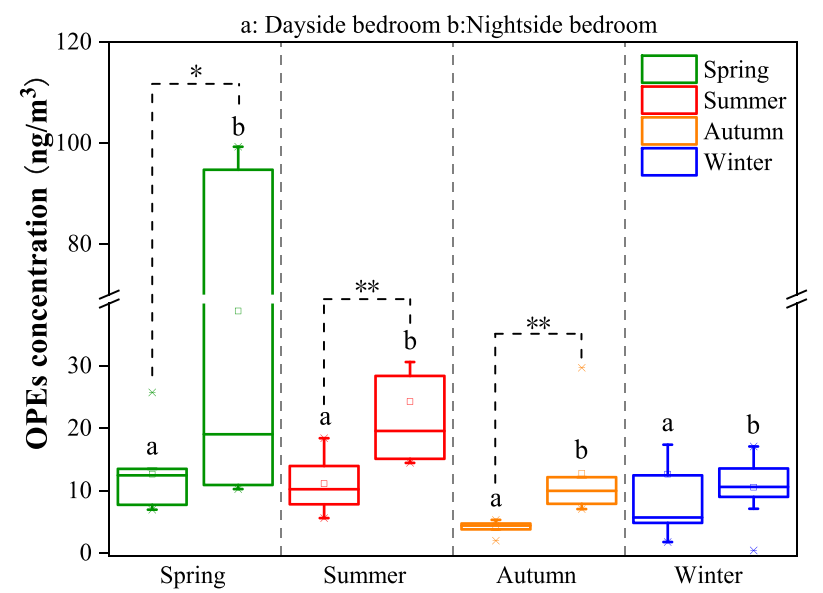

Fig. 2. Concentrations of OPEs in PM samples from two bedrooms in four seasons. Asterisks indicate significant $(\mathrm{p}<0.05$ or $\mathrm{p}<0.01$ ) higher concentrations in nightside bedroom than in dayside bedroom

\subsubsection{Principal Component Analysis}

Principal Component Analysis (PCA) was applied to explore the possible sources of OPEs in PM samples from different rooms. As shown in Fig. S3, three principal components (PC1, PC2, and PC3) were extracted which accounted for $55.5 \%$ of the total variances. PC1 explained $21.4 \%$ of the total variances and was dominated by lower molecular weight OPEs with a loading of $0.80,0.72$, and 0.70 for TIBP, TIPP, and TPeP, respectively (Fig. S3A). The score plot (Fig. S3C) showed that the largest contribution for PC1 happened in bedrooms from spring and summer samples, corresponding to their more volatile properties at higher temperature. TIBP and TIPP are mostly used as plasticizers in polymers, rubber and plastics (Andresen and Bester, 2006). Thus, loading of OPEs in PC1 relates to the sources originating from children toys in nightside bedroom and floor leather in dayside bedroom (Fig. S1). PC2 explained

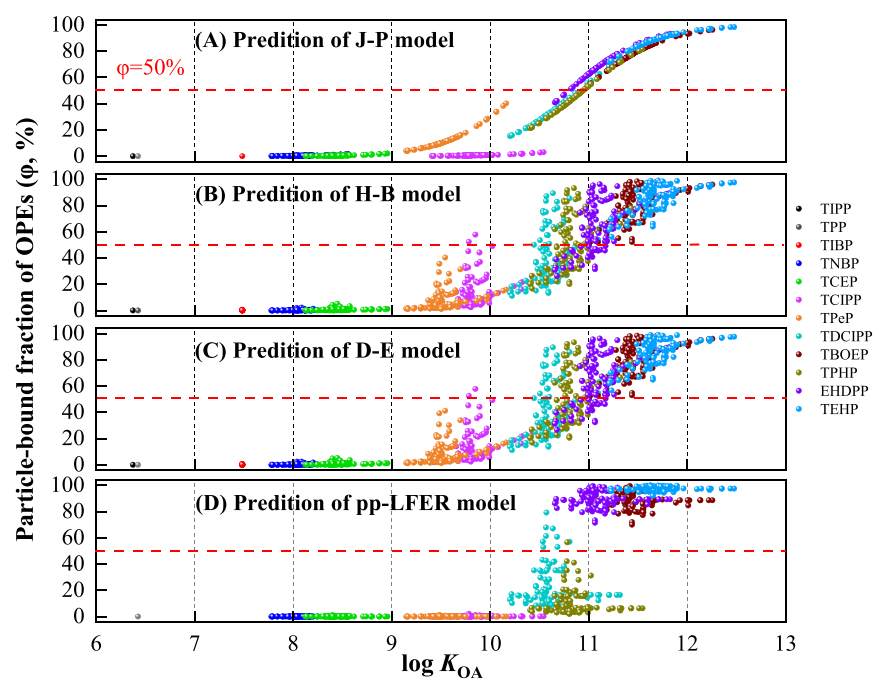

Fig. 3. Comparisons of predicted particle-bound fractions of individual OPEs on basis of different partitioning models. 
$18.1 \%$ of the total variances and was dominated by three chlorinated OPEs, i.e., TDCIPP (0.83), TCIPP (0.79), and TCEP (0.64) (Fig. S3A). The score plot (Fig. S3C) showed that the largest contribution for PC2 happened in living room and dayside bedroom. A main source for chlorinated OPEs is from flexible and rigid polyurethane foam (PUFs) (Marklund et al., 2003; Stapleton et al., 2009; Van der Veen and de Boer, 2012). This result suggested that emissions from sofa containing large amount of PUFs between living room and dayside bedroom might be a significant source of these OPEs (Fig. S1). PC3 explained $16.0 \%$ of the total variances and was heavily influenced by TPHP $(0.93)$ and TEHP (0.96) (Fig. S3B). The score plot (Fig. S3D) showed that the largest contribution for PC3 happened in nightside bedroom. TPHP and TEHP can be used as both plasticizers and flame retardants in consumer products. Wang et al. found TPHP and TEHP were the main components in PVC materials (Wang et al., 2017). Thus, this result suggests that abrasion of PVC materials, e.g., window frame, might be main source of these non-volatile OPEs (Fig. S1).

\subsection{Prediction of OPEs particle fraction by gas/particle partitioning model}

Once released to the indoor environments, OPEs will be redistributed between the gas phase and particle phase in indoor air. In addition, unlike the outdoor environment, the influence factors in indoor environments are stable, considering the OPE gas/particle partitioning in the equilibrium state. Four equilibrium model, including the J-P model, H-B model, D-E model, and pp-LFER model, were applied to estimate the OPE gas phase concentrations using the particle-bound fraction $(\varphi)$ or gas/particle partitioning coefficient $\left(K_{\mathrm{P}}\right)$ in indoor air. Detail information of four equilibrium models is shown in SM S2, and the relevant parameters involved in these models for individual OPEs are shown in Tables S12-S13.

As shown in Fig. 3, regardless of individual OPEs, the predicted $\varphi_{\mathrm{H}-\mathrm{B}}$ and $\varphi_{\mathrm{D}-\mathrm{E}}$ have positive correlations with $\log K_{\mathrm{OA}}$ while the $\varphi_{\mathrm{J}-\mathrm{P}}$ has a negative correlation with $\log P_{\mathrm{L}}^{\mathrm{o}}$. OPEs with $\log K_{\mathrm{OA}}>10.51$ or $\log P_{\mathrm{L}}^{\mathrm{o}}<-3.75$, including TBOEP, EHDPP, and TEHP, have the estimated particle fractions $>50 \%$. The median model-based gas fractions of TIPP, TPP, TIBP, TNBP, and TCEP in four models were nearly $100 \%$, indicating that these relatively more volatile OPEs exclusively exist in the gas phase. Meanwhile, the particle fractions of TBOEP, EHDPP, and TEHP ranged from $65.7 \%$ to $97.4 \%$ and the results indicated that these OPEs tended to be in the particle phase. Additionally, TCIPP, TPeP, and TDCIPP were predicted to be mainly in the gas phase with the gas fractions ranging from $60.5 \%$ to $100 \%$ and the gas fractions estimated by the pp-LFER model were much higher than those estimated by the other three models. TPHP was evenly distributed between the gas phase and the particle phase with the particle fraction for the J-P model, H-B model, and D-E model being 42.1\%, 51.1\% and 51.7\%, respectively. However, TPHP based on the pp-LFER model is mainly in the gas phase $(\varphi=$ $6.33 \%)$.

Due to the lower air sampling volume in indoor environments, the current studies of G/P partitioning are mainly concentrated on the outdoor atmosphere. The reported OPE particle fractions in Beijing-TianjinHebei (BTH, China) region ranged from $77 \%$ for TCIPP to $88 \%$ for TPHP (87\% for TEHP and 86\% for TCEP) (Zhang et al., 2019), whereas in the North Huangcheng Island (NHI, China), the fractions ranged from $72 \%$ for TNBP to $83 \%$ for TCIPP ( $83 \%$ for TCEP and $82 \%$ for TIBP) (Li et al., 2018). Other studies for other countries on outdoor atmosphere and limited indoor air also showed higher particle fractions (Carlsson et al., 1997; Moller et al., 2011; Li et al., 2017b). However, the higher indoor temperature and lower TSP concentrations may lead to elevated OPE concentration in the gas phase, which has been proven by OPEs and other SVOCs (Moreau-Guigon et al., 2016; Okeme et al., 2018). The particle fractions of OPEs with $\log K_{\mathrm{OA}}>10.51$ that predicted by all four models in this study generally well matched the measured $\varphi$ in the literatures above. However, the estimated particle fractions of OPEs with $\log K_{\mathrm{OA}}<10.51$ were underestimate, contrary to the reported results (Li et al., 2018; Zhang et al., 2019). This difference could be attributed to the strong polarity of these OPEs, leading to the stronger ability sorbed from gas phase to particles and/or to quartz fiber filters used during air sampling (Arp et al., 2007; Brommer et al., 2014; Okeme et al., 2018). As discussed above, the correlations between OPEs and OC were more significant than those between OPEs and EC, indicating that the dominant absorption effect of organic matter in particle on OPEs. The absorption mechanism of organic matter dominates $\mathrm{G}$ / $\mathrm{P}$ partitioning of OPEs has also been predicted in the BTH region (Zhang et al., 2019). Therefore, a single adsorption (J-P) model or absorption (H-B) model is not accurate for the gas particle partitioning. The ppLFER model proposed by Goss (Goss, 2005) was a more complex model, considering the $\mathrm{G} / \mathrm{P}$ partitioning at the sorbing phase and molecule level. However, relative to the D-E model optimizing the TSP, $f_{\mathrm{OM}}$, $f_{\mathrm{EC}}$ and other parameters of each sample, the underestimation of TPHP particle fraction by the pp-LFER model indicated that this model for OPEs still needed to be further optimized.

\subsection{Human exposure and risk assessment of OPEs for indoor air and dust}

In this section, the estimated daily intakes (EDIs) of OPEs for different age groups from indoor air via inhalation and dust via ingestion and dermal absorption were determined. The measured concentrations in PM of OPEs with $\log K_{\mathrm{OA}}<10.51$ were regarded as the sum of gas and particle phases while the gas phase concentrations of OPEs with log $K_{\mathrm{OA}}>10.51$ were estimated from the measured particle phase concentrations by the D-E model. The dust concentrations were derived from unpublished data and the details are listed in Table S14. For chemicals with carcinogenic toxicities, such as TNBP, TCEP, TDCIPP, and TEHP, the carcinogenic risk (CR) was estimated. The detailed calculation process and the values of the parameters for EDI and CR can be found in SM S3 and Table S15.

\subsubsection{Estimated daily intakes}

The EDI values of OPEs for different age groups from both indoor air and dust are summarized in Table S16. The median EDI for toddlers (48.0 ng/kg-bw/day) from indoor environment was the highest, followed by infants (42.0 ng/kg-bw/day), children (36.2 ng/kg-bw/ day), teenagers (20.7 ng/kg-bw/day) and adults (11.8.0 ng/kg-bw/ day), suggesting the much more sensitivity to OPE exposure for young people than adults. The estimated EDIs in this study were comparable with the EDIs calculated in Beijing (Wu et al., 2016; Cao et al., 2019a; Wang et al., 2019) and Guangdong (He et al., 2015; Zheng et al., 2015; Zheng et al., 2017), China. Additionally, TCIPP was the most abundant OPE for all age group exposure with the EDIs ranging from $4.16 \mathrm{ng} / \mathrm{kg}$ bw/day to13.1 ng/kg-bw/day. OPEs can enter the human body via air inhalation, dust ingestion, and dust dermal absorption (Xu et al., 2016). As illustrated in Fig. S4, in terms of exposure routes, ingestion or inhalation was the main route to the different molecular weight OPEs. For OPEs with lower molecular weight including TIPP, TIBP, and TNBP, inhalation was the main exposure route whereas ingestion contributed the most for higher molecular weight OPEs, such as TBOEP, TPHP, EHDPP, and TEHP. And the EDIs of these OPEs are some orders of magnitude lower than the oral reference dose (RfD) values.

\subsubsection{Carcinogenic risk assessment}

The carcinogenic risks were assessed based on the slope factors (USEPA, 2020). The CR values of TNBP, TCEP, TDCIPP, and TEHP for different age groups from indoor dust are shown in Table S17. People are considered to have a potential carcinogenic risk if the $\mathrm{CR}$ value is $>1 \times 10^{-6}$. The CR values of individual OPEs for different age groups were all within the acceptable level $\left(C R<1 \times 10^{-6}\right)$ even in the worst scenario (the CR were calculated on the basis of maximum OPE concentrations). The median CR values of OPEs were in the ranges of $3.78 \times 10^{-8}$ to $6.26 \times 10^{-7}$. These values were less one order of magnitude lower than $1 \times 10^{-6}$, suggesting a potential deleterious risk 
associated with OPE exposure via indoor dust. However, it is worth noting that only the carcinogenic risk of indoor dust via ingestion and dermal absorption were considered due to the lack of inhalation slope factors $\left(S F_{\mathrm{INH}}\right)$.

\section{Conclusion and implication}

In this study, 104 indoor PM samples were collected and analyzed to study the occurrence, influence factors, potential sources, G/P partitioning, human exposure, and risk assessment of OPEs in indoor environment. The $\Sigma_{12} \mathrm{OPEs}$ concentrations ranged from $0.41 \mathrm{ng} / \mathrm{m}^{3}$ to $940 \mathrm{ng} / \mathrm{m}^{3}$ in the test home and TCIPP was the most abundant OPE. The concentration of $\Sigma_{12}$ OPEs in warmer seasons was higher than those in autumn and winter. Compared with the temperature and relative humidity, outdoor TSP was the main factor that affected the OPE concentration variation in PM samples from indoors. Comparisons of different gas/particle partitioning models suggested that the D-E model estimates were more reliable. The strongly absorption of gas phase low molecular weight OPEs to filters might explain their mismatch with the models. For lower molecular weight OPEs, inhalation was the main exposure route whereas ingestion contributed the most for higher molecular weight OPEs. The EDIs and CRs posed by OPEs were all below the recommended values, indicating that the current OPE levels in the test home were within the safe thresholds.

There are still limitations of this study. First of all, in the case of good air quality, the sampling volume is small and cannot obtain sufficient TSP to weigh. Exploring sampling method to collect bigger sample volume and simultaneously avoid a big interference on air flow in indoor environment is highly required. Secondly, only particle phase OPEs were collected, this makes it impossible to verify the OPE concentration in gas phase predicted by the gas particle partitioning model. Thirdly, only 5 mixed dust samples (a mixture of dust collected from dayside bedroom, nightside bedroom, and living room) were collected during the entire sampling period due to the lack of human activity and poor ventilation, resulting in a lack of universality for exposure and risk assessment. In addition, since the house is not newly built, the EDIs and CRs may be underestimated for different age groups from air and dust in home. However, our research has reference value, and provides comprehensive results on the seasonal variation and influence factors of OPEs in indoor PM.

\section{CRediT authorship contribution statement}

Yu Sun: Investigation, Methodology, Validation, Formal analysis, Data curation, Writing - original draft, Visualization. Jia-Qi Guo: Data curation, Investigation, Validation. Li-Yan Liu: Conceptualization, Supervision, Resources, Writing - review \& editing. Ed Sverko: Writing review \& editing. Zhi Zhang: Resources. Chong-Guo Tian: Resources. Chun-Yan Huo: Investigation, Validation. Hai-Ling Li: Formal analysis. Wan-Li Ma: Resources, Writing - review \& editing. Zi-Feng Zhang: Resources, Writing - review \& editing. Wei-Wei Song: Resources, Writing review \& editing. Yi-Fan Li: Resources, Project administration, Writing review \& editing. Li Wang: Writing - review \& editing.

\section{Declaration of competing interest}

The authors declare no competing financial interests.

\section{Acknowledgements}

This work was supported by the Open Project of State Key Laboratory of Urban Water Resource and Environment (Harbin Institute of Technology) (No. ESK201702).

\section{Appendix A. Supplementary data}

Supplementary data to this article can be found online at https://doi. org/10.1016/j.scitotenv.2020.140048.

\section{References}

Abdallah, M.A., Covaci, A., 2014. Organophosphate flame retardants in indoor dust from Egypt: implications for human exposure. Environ. Sci. Technol. 48, 4782-4789.

Andresen, J., Bester, K., 2006. Elimination of organophosphate ester flame retardants and plasticizers in drinking water purification. Water Res. 40, 621-629.

Andresen, J.A., Grundmann, A., Bester, K., 2004. Organophosphorus flame retardants and plasticisers in surface waters. Sci. Total Environ. 332, 155-166.

Araki, A., Saito, I., Kanazawa, A., Morimoto, K., Nakayama, K., Shibata, E., Tanaka, M., Takigawa, T., Yoshimura, T., Chikara, H., Saijo, Y., Kishi, R., 2014. Phosphorus flame retardants in indoor dust and their relation to asthma and allergies of inhabitants. Indoor Air 24, 3-15.

Arp, H.P.H., Schwarzenbach, R.P., Goss, K.U., 2007. Equilibrium sorption of gaseous organic chemicals to fiber filters used for aerosol studies. Atmos. Environ. 41, 8241-8252.

Bergh, C., Torgrip, R., Ostman, C., 2010. Simultaneous selective detection of organophosphate and phthalate esters using gas chromatography with positive ion chemical ionization tandem mass spectrometry and its application to indoor air and dust. Rapid Commun. Mass Spectrom. 24, 2859-2867.

Brommer, S., Jantunen, L.M., Bidleman, T.F., Harrad, S., Diamond, M.L., 2014. Determination of vapor pressures for organophosphate esters. J. Chem. Eng. Data 59, 1441-1447.

Cao, Z.G., Xu, F.C., Covaci, A., Wu, M., Yu, G., Wang, B., Deng, S.B., Huang, J., 2014. Differences in the seasonal variation of brominated and phosphorus flame retardants in office dust. Environ. Int. 65, 100-106.

Cao, D.D., Lv, K., Gao, W., Fu, J., Wu, J., Fu, J.J., Wang, Y.W., Jiang, G.B., 2019a. Presence and human exposure assessment of organophosphate flame retardants (OPEs) in indoor dust and air in Beijing, China. Ecotox. Environ. Safe. 169, 383-391.

Cao, Z., Zhao, L., Zhang, Y., Ren, M., Zhang, Y., Liu, X., Jie, J., Wang, Z., Li, C., Shen, M., Bu, Q., 2019b. Influence of air pollution on inhalation and dermal exposure of human to organophosphate flame retardants: a case study during a prolonged haze episode. Environ. Sci. Technol. 53, 3880-3887.

Carlsson, H., Nilsson, U., Becker, G., Ostman, C., 1997. Organophosphate ester flame retardants and plasticizers in the indoor environment: analytical methodology and occurrence. Environ. Sci. Technol. 31, 2931-2936.

Cequier, E., Ionas, A.C., Covaci, A., Maria Marce, R., Becher, G., Thomsen, C., 2014. Occurrence of a broad range of legacy and emerging flame retardants in indoor environments in Norway. Environ. Sci. Technol. 48, 6827-6835.

Cristale, J., Dantas, R.F., De Luca, A., Sans, C., Esplugas, S., Lacorte, S., 2017. Role of oxygen and DOM in sunlight induced photodegradation of organophosphorous flame retardants in river water. J. Hazard. Mater. 323, 242-249.

Dachs, J., Eisenreich, S.J., 2000. Adsorption onto aerosol soot carbon dominates gasparticle partitioning of polycyclic aromatic hydrocarbons. Environ. Sci. Technol. 34, 3690-3697.

Fromme, H., Lahrz, T., Hainsch, A., Oddoy, A., Piloty, M., Ruden, H., 2005. Elemental carbon and respirable particulate matter in the indoor air of apartments and nursery schools and ambient air in Berlin (Germany). Indoor Air 15, 335-341.

Goss, K.U., 2005. Predicting the equilibrium partitioning of organic compounds using just one linear solvation energy relationship (LSER). Fluid Phase Equilib. 233, 19-22.

Harner, T., Bidleman, T.F., 1998. Octanol-air partition coefficient for describing particle/gas partitioning of aromatic compounds in urban air. Environ. Sci. Technol. 32, 1494-1502.

He, C.T., Zheng J., Oiao, L., Chen, S.J., Yang J.Z., Yuan, J.G., Yang, Z.Y., Mai, B.X., 2015. Occurrence of organophosphorus flame retardants in indoor dust in multiple microenvironments of southern China and implications for human exposure. Chemosphere $133,47-52$

He, C., Wang, X.Y., Thai, P., Baduel, C., Gallen, C., Banks, A., Bainton, P., English, K., Mueller, J.F., 2018. Organophosphate and brominated flame retardants in Australian indoor environments: levels, sources, and preliminary assessment of human exposure. Environ. Pollut. 235, 670-679.

Hou, R., Xu, Y.P., Wang, Z.J., 2016. Review of OPFRs in animals and humans: absorption, bioaccumulation, metabolism, and internal exposure research. Chemosphere 153, 78-90.

Kanazawa, A., Saito, I., Araki, A., Takeda, M., Ma, M., Saijo, Y., Kishi, R., 2010. Association between indoor exposure to semi-volatile organic compounds and building-related symptoms among the occupants of residential dwellings. Indoor Air 20, 72-84.

Kim, U.J., Wang, Y., Li, W.H., Kannan, K., 2019. Occurrence of and human exposure to organophosphate flame retardants/plasticizers in indoor air and dust from various microenvironments in the United States. Environ. Int. 125, 342-349.

Lai, N.L.S., Kwok, K.Y., Wang, X.H., Yamashita, N., Liu, G.J., Leung, K.M.Y., Lam, P.K.S., Lam, J.C.W., 2019. Assessment of organophosphorus flame retardants and plasticizers in aquatic environments of China (Pearl River Delta, South China Sea, Yellow River Estuary) and Japan (Tokyo Bay). J. Hazard. Mater. 371, 288-294.

Li, C., Chen, J.W., Xie, H.B., Zhao, Y.H., Xia, D.M., Xu, T., Li, X.H., Qiao, X.L., 2017a. Effects of atmospheric water on $\cdot \mathrm{OH}$-initiated oxidation of organophosphate flame retardants: a DFT investigation on TCPP. Environ. Sci. Technol. 51, 5043-5051.

Li, J., Xie, Z.Y., Mi, W.Y., Lai, S.C., Tian, C.G., Emeis, K.C., Ebinghaus, R., 2017b. Organophosphate esters in air, snow, and seawater in the North Atlantic and the Arctic. Environ. Sci. Technol. 51, 6887-6896. 
Li, J., Tang, J.H., Mi, W.Y., Tian, C.G., Emeis, K.C., Ebinghaus, R., Xie, Z.Y., 2018. Spatial distribution and seasonal variation of organophosphate esters in air above the Bohai and Yellow Seas, China. Environ. Sci. Technol. 52, 89-97.

Li, W.H., Wang, Y., Asimakopoulos, A.G., Covaci, A., Gevao, B., Johnson-Restrepo, B. Kumosani, T.A., Malarvannan, G., Moon, H.B., Nakata, H., Sinha, R.K., Tran, T.M., Kannan, K., 2019. Organophosphate esters in indoor dust from 12 countries: concentrations, composition profiles, and human exposure. Environ. Int. 133.

Liang, K., Liu, J., 2016. Understanding the distribution, degradation and fate of organophosphate esters in an advanced municipal sewage treatment plant based on mass flow and mass balance analysis. Sci. Total Environ. 544, 262-270.

Liu, Y., Huang, L., Li, S.M., Harner, T., Liggio, J., 2014a. OH-initiated heterogeneous oxidation of tris-2-butoxyethyl phosphate: implications for its fate in the atmosphere. Atmos. Chem. Phys. 14, 12195-12207.

Liu, Y., Liggio, J., Harner, T., Jantunen, L., Shoeib, M., Li, S.-M., 2014b. Heterogeneous OH initiated oxidation: a possible explanation for the persistence of organophosphate flame retardants in air. Environ. Sci. Technol. 48, 1041-1048.

Liu, Q.F., Liggio, J., Li, K., Lee, P., Li, S.M., 2019. Understanding the impact of relative humidity and coexisting soluble iron on the $\mathrm{OH}$-initiated heterogeneous oxidation of organophosphate flame retardants. Environ. Sci. Technol. 53, 6794-6803.

Luongo, G., Ostman, C., 2016. Organophosphate and phthalate esters in settled dust from apartment buildings in Stockholm. Indoor Air 26, 414-425.

Ma, J., Chen, L.L., Guo, Y., Wu, Q., Yang, M., Wu, M.H., Kannan, K., 2014. Phthalate diesters in airborne $\mathrm{PM}_{2.5}$ and $\mathrm{PM}_{10}$ in a suburban area of Shanghai: seasonal distribution and risk assessment. Sci. Total Environ. 497, 467-474.

Marklund, A., Andersson, B., Haglund, P., 2003. Screening of organophosphorus compounds and their distribution in various indoor environments. Chemosphere 53, 1137-1146.

Marklund, A., Andersson, B., Haglund, P., 2005. Organophosphorus flame retardants and plasticizers in air from various indoor environments. J. Environ. Monit. 7, 814-819.

Mizouchi, S., Ichiba, M., Takigami, H., Kajiwara, N., Takamuku, T., Miyajima, T., Kodama, H., Someya, T., Ueno, D., 2015. Exposure assessment of organophosphorus and organobromine flame retardants via indoor dust from elementary schools and domestic houses. Chemosphere 123, 17-25.

Moller, A., Xie, Z.Y., Caba, A., Sturm, R., Ebinghaus, R., 2011. Organophosphorus flame retardants and plasticizers in the atmosphere of the North Sea. Environ. Pollut. 159, 3660-3665.

Moreau-Guigon, E., Alliot, F., Gasperi, J., Blanchard, M., Teil, M.J., Mandin, C., Chevreuil, M., 2016. Seasonal fate and gas/particle partitioning of semi-volatile organic compounds in indoor and outdoor air. Atmos. Environ. 147, 423-433.

Okeme, J.O., Rodgers, T.F.M., Jantunen, L.M., Diamond, M.L., 2018. Examining the gasparticle partitioning of organophosphate esters: how reliable are air measurements? Environ. Sci. Technol. 52, 13834-13844.

Pang, L., Yang, H.Q., Wang, Y., Luo, X.L., Liu, S.J., Xiao, J.W., 2019. Organophosphate flame retardants in total suspended particulates from an urban area of Zhengzhou, China: temporal variations, potential affecting factors, and health risk assessment. Ecotox. Environ. Safe. 176, 204-210.

Pankow, J.F., 1987. Review and comparative-analysis of the theories on partitioning between the gas and aerosol particulate phases in the atmosphere. Atmos. Environ. 21, 2275-2283.

Saito, I., Onuki, A., Seto, H., 2007. Indoor organophosphate and polybrominated flame retardants in Tokyo. Indoor Air 17, 28-36.

Salamova, A., Ma, Y.N., Venier, M., Hites, R.A., 2014. High levels of organophosphate flame retardants in the Great Lakes atmosphere. Environ. Sci. Technol. Lett. 1, 8-14.

Salthammer, T., Goss, K.U., 2019. Predicting the gas/particle distribution of SVOCs in the indoor environment using poly parameter linear free energy relationships. Environ. Sci. Technol. 53, 2491-2499.

Shen, G., Wang, W., Yang, Y., Ding, J., Xue, M., Min, Y., Zhu, C., Shen, H., Li, W., Wang, B., Wang, R., Wang, X., Tao, S., Russell, A.G., 2011. Emissions of PAHs from indoor crop residue burning in a typical rural stove: emission factors, size distributions, and gas-particle partitioning. Environ. Sci. Technol. 45, 1206-1212.

Stapleton, H.M., Klosterhaus, S., Eagle, S., Fuh, J., Meeker, J.D., Blum, A., Webster, T.F., 2009. Detection of organophosphate flame retardants in furniture foam and U.S. house dust. Environ. Sci. Technol. 43, 7490-7495.

Suhring, R., Wolschke, H., Diamond, M.L., Jantunen, L.M., Scheringer, M., 2016. Distribution of organophosphate esters between the gas and particle phase-model predictions vs measured data. Environ. Sci. Technol. 50, 6644-6651.

Takeuchi, S., Kojima, H., Saito, I., Jin, K., Kobayashi, S., Tanaka-Kagawa, T., Jinno, H., 2014. Detection of 34 plasticizers and 25 flame retardants in indoor air from houses in Sapporo, Japan. Sci. Total Environ. 491, 28-33.
Takeuchi, S., Tanaka-Kagawa, T., Saito, I., Kojima, H., Jin, K., Satoh, M., Kobayashi, S., Jinno, H., 2018. Differential determination of plasticizers and organophosphorus flame retardants in residential indoor air in Japan. Environ. Sci. Pollut. Res. 25, 7113-7120.

Tan, X.X., Luo, X.J., Zheng, X.B., Li, Z.R., Sun, R.X., Mai, B.X., 2016. Distribution of organophosphorus flame retardants in sediments from the Pearl River Delta in South China. Sci. Total Environ. 544, 77-84.

Tao, F., Sellstrom, U., de Wit, C.A., 2019. Organohalogenated flame retardants and organophosphate esters in office air and dust from Sweden. Environ. Sci. Technol. 53, 2124-2133.

USEPA, 2020. Mid Atlantic risk assessment. Regional screening level (RSL) summary table (Washington DC). http://www.epa.gov/reg3hwmd/risk/human/rb-concentration table/.

Van den Eede, N., Dirtu, A.C., Ali, N., Neels, H., Covaci, A., 2012. Multi-residue method for the determination of brominated and organophosphate flame retardants in indoor dust. Talanta 89, 292-300.

Van der Veen, I., de Boer, J., 2012. Phosphorus flame retardants: properties, production, environmental occurrence, toxicity and analysis. Chemosphere 88, 1119-1153.

Vykoukalova, M., Venier, M., Vojta, S., Melymuk, L., Becanova, J., Romanak, K., Prokes, R., Okeme, J.O., Saini, A., Diamond, M.L., Klanova, J., 2017. Organophosphate esters flame retardants in the indoor environment. Environ. Int. 106, 97-104.

Wan, W., Zhang, S., Huang, H., Wu, T., 2016. Occurrence and distribution of organophosphorus esters in soils and wheat plants in a plastic waste treatment area in China. Environ. Pollut. 214, 349-353.

Wang, R., Tang, J., Xie, Z., Mi, W., Chen, Y., Wolschke, H., Tian, C., Pan, X., Luo, Y., Ebinghaus, R., 2015. Occurrence and spatial distribution of organophosphate ester flame retardants and plasticizers in 40 rivers draining into the Bohai Sea, north China. Environ. Pollut. 198, 172-178.

Wang, Y., Hou, M.M., Zhang, Q.N., Wu, X.W., Zhao, H.X., Xie, Q., Chen, J.W., 2017. Organophosphorus flame retardants and plasticizers in building and decoration materials and their potential burdens in newly decorated houses in China. Environ. Sci. Technol. 51, 10991-10999.

Wang, D., Wang, P., Wang, Y.W., Zhang, W.W., Zhu, C.F., Sun, H.Z., Matsiko, J., Zhu, Y., Li, Y.M., Meng, W.Y., Zhang, Q.H., Jiang, G.B., 2019. Temporal variations of PM $_{2.5}$-bound organophosphate flame retardants in different microenvironments in Beijing, China, and implications for human exposure. Sci. Total Environ. 666, 226-234.

Wei, G.L., Li, D.Q., Zhuo, M.N., Liao, Y.S., Xie, Z.Y., Guo, T.L., Li, J.J., Zhang, S.Y., Liang, Z.Q 2015. Organophosphorus flame retardants and plasticizers: sources, occurrence, toxicity and human exposure. Environ. Pollut. 196, 29-46.

Wensing, M., Uhde, E., Salthammer, T., 2005. Plastics additives in the indoor environment - flame retardants and plasticizers. Sci. Total Environ. 339, 19-40.

Wolschke, H., Suhring, R., Mi, W.Y., Moller, A., Xie, Z.Y., Ebinghaus, R., 2016. Atmospheric occurrence and fate of organophosphorus flame retardants and plasticizer at the German coast. Atmos. Environ. 137, 1-5.

Wu, M., Yu, G., Cao, Z.G., Wu, D.K., Liu, K., Deng, S.B., Huang, J., Wang, B., Wang, Y.J., 2016 Characterization and human exposure assessment of organophosphate flame retardants in indoor dust from several microenvironments of Beijing, China. Chemosphere $150,465-471$.

Xu, F., Giovanoulis, G., van Waes, S., Padilla-Sanchez, J.A., Papadopoulou, E., Magner, J., Haug, L.S., Neels, H., Covaci, A., 2016. Comprehensive study of human external exposure to organophosphate flame retardants via air, dust, and hand wipes: the importance of sampling and assessment strategy. Environ. Sci. Technol. 50, 7752-7760.

Yang, F., Ding, J., Huang, W., Xie, W., Liu, W., 2014. Particle size-specific distributions and preliminary exposure assessments of organophosphate flame retardants in office air particulate matter. Environ. Sci. Technol. 48, 63-70.

Zhang, W., Wang, P., Li, Y., Wang, D., Matsiko, J., Yang, R., Sun, H., Hao, Y., Zhang, Q., Jiang, G., 2019. Spatial and temporal distribution of organophosphate esters in the atmosphere of the Beijing-Tianjin-Hebei region, China. Environ. Pollut. 244, 182-189.

Zheng, X.B., Xu, F.C., Chen, K.H., Zeng, Y.H., Luo, X.J., Chen, S.J., Mai, B.X., Covaci, A., 2015 Flame retardants and organochlorines in indoor dust from several e-waste recycling sites in South China: composition variations and implications for human exposure. Environ. Int. 78, 1-7.

Zheng, X.B., Qiao, L., Covaci, A., Sun, R.X., Guo, H.Y., Zheng, J., Luo, X.J., Xie, Q.L., Mai, B.X. 2017. Brominated and phosphate flame retardants (FRs) in indoor dust from different microenvironments: implications for human exposure via dust ingestion and dermal contact. Chemosphere 184, 185-191.

Zhou, L.L., Hiltscher, M., Gruber, D., Puttmann, W., 2017. Organophosphate flame retardants (OPFRs) in indoor and outdoor air in the Rhine/Main area, Germany: comparison of concentrations and distribution profiles in different microenvironments. Environ. Sci. Pollut. Res. 24, 10992-11005. 